\title{
Cytomegalovirus Reactivation Induced Acute Hepatitis and Gastric Erosions in a Patient with Rheumatoid Arthritis under Treatment with an Anti-IL-6 Receptor Antibody, Tocilizumab
}

\author{
Takuya Komura ${ }^{1,2}$, Hajime Ohta ${ }^{1}$, Ryotaro Nakai ${ }^{1}$, Jun Seishima ${ }^{1}$, Masatoshi Yamato ${ }^{1}$, \\ Masaki Miyazawa ${ }^{1}$, Kiichiro Kaji ${ }^{1}$, Yohei Marukawa ${ }^{1}$, Takashi Kagaya ${ }^{1}$, Kiyoki Kitagawa ${ }^{3}$, \\ Atsuhiro Kawashima ${ }^{4}$, Shuichi Kaneko ${ }^{2}$ and Masashi Unoura ${ }^{1}$
}

\begin{abstract}
Tocilizumab, an anti-human interleukin 6 receptor (IL-6R) monoclonal antibody, is widely used to treat rheumatoid arthritis (RA) and is expected to exhibit clinical efficacy when used to treat other autoimmune diseases. However, a risk of opportunistic infection is occasionally recognized. A 54-year-old woman had received an oral corticosteroid and methotrexate to treat RA. Despite receiving these treatments, she received additional treatment with tocilizumab due to poor control of the disease activity. She presented at our hospital with a high fever and epigastralgia 19 days after receiving this treatment. A laboratory evaluation revealed liver injury and cytomegalovirus (CMV) viremia. Abdominal ultrasonography and computed tomography (CT) revealed hepatosplenomegaly, but no ascites. Upper gastrointestinal endoscopy revealed gastric erosions induced by CMV, which were confirmed immunohistochemically. Hence, we diagnosed the patient with CMV reactivation-induced acute hepatitis and gastric erosions under tocilizumab treatment. She received an anti-cytomegalovirus drug, ganciclovir, for 14 days due to her viremia and impaired general condition, which was suggestive of a severe infection. Her general condition subsequently improved, the liver function test results normalized, and the gastric erosions disappeared. In conclusion, although tocilizumab is very useful for treating certain autoimmune and inflammatory diseases, and will be prescribed more widely in the future, associated CMV infections must be closely monitored, as these can be lethal.
\end{abstract}

Key words: cytomegalovirus, acute hepatitis, tocilizumab, IL-6

(Intern Med 55: 1923-1927, 2016)

(DOI: 10.2169/internalmedicine.55.5981)

\section{Introduction}

Rheumatoid arthritis (RA) is a chronic inflammatory disease of the joints and surrounding tissues associated with intense pain, irreversible joint destruction, and various systemic complications (1). In patients with RA, the level of interleukin 6 (IL-6) is elevated in both the serum and synovial fluid, indicating that IL-6 plays a key role in RA progres- sion (2). The activities of IL-6 and the receptor thereof, IL$6 \mathrm{R}$, play crucial roles in the pathogenesis of several diseases $(3,4)$. Blocking of IL-6/IL-6R complex formation is expected to become a valuable therapeutic strategy in the treatment of several inflammatory and autoimmune diseases (5).

Tocilizumab (ACTEMRA ${ }^{\mathrm{TM}}$ ) is a recombinant humanized anti-human IL-6R monoclonal antibody classified as a biological disease modifier (6). Recently, the drug has been

\footnotetext{
${ }^{1}$ Department of Gastroenterology, National Hospital Organization Kanazawa Medical Center, Japan, ${ }^{2}$ Disease Control and Homeostasis, Kanazawa University, Japan, ${ }^{3}$ Department of Internal Medicine, National Hospital Organization Kanazawa Medical Center, Japan and ${ }^{4}$ Department of Clinical Laboratory, National Hospital Organization Kanazawa Medical Center, Japan

Received for publication June 15, 2015; Accepted for publication October 7, 2015
}

Correspondence to Dr. Takuya Komura, t.komura@m-kanazawa.jp 
Table. Laboratory Data on Admission.

\begin{tabular}{|c|c|c|c|c|c|c|c|c|}
\hline WBC & 8.2 & $\times 10^{3} / \mu \mathrm{L}$ & BUN & 11.9 & $\mathrm{mg} / \mathrm{dL}$ & CMV-IgG & 13.4 & IU/L \\
\hline $\mathrm{Neu}$ & 32.0 & $\%$ & $\mathrm{Cr}$ & 0.69 & $\mathrm{mg} / \mathrm{d} \mathrm{L}$ & CMV-IgM & 3.7 & $\mathrm{IU} / \mathrm{L}$ \\
\hline Lym & 55.0 & $\%$ & T-Bil & 1.3 & $\mathrm{mg} / \mathrm{d} \mathrm{L}$ & CMV-Antigenemia & $14 / 22$ & Positive cells \\
\hline Mono & 11.0 & $\%$ & TP & 5.6 & $\mathrm{~g} / \mathrm{dL}$ & EBV-VCA-IgG & 640 & $\mathrm{U} / \mathrm{L}$ \\
\hline Eosin & 0.6 & $\%$ & Alb & 3.1 & $\mathrm{~g} / \mathrm{dL}$ & EBV-VCA-IgM & 10 & $\mathrm{ng} / \mathrm{dL}$ \\
\hline Aty-lym & 4 & $\%$ & AST & 63 & $\mathrm{IU} / \mathrm{L}$ & EBNA & 20 & \\
\hline $\mathrm{RBC}$ & 4.21 & $10^{6} / \mu \mathrm{L}$ & ALT & 106 & $\mathrm{IU} / \mathrm{L}$ & HA-IgM & $(-)$ & $\mathrm{mg} / \mathrm{dL}$ \\
\hline $\mathrm{Hb}$ & 12.5 & $\mathrm{~g} / \mathrm{dl}$ & LDH & 410 & $\mathrm{IU} / \mathrm{L}$ & HBs-Ag & $(-)$ & $\mathrm{mg} / \mathrm{dL}$ \\
\hline \multirow[t]{2}{*}{ Plts } & 25.7 & $\times 10^{4} / \mu \mathrm{L}$ & ALP & 498 & $\mathrm{IU} / \mathrm{L}$ & HBc-IgM & $(-)$ & \\
\hline & & & Y-GTP & 276 & $\mathrm{IU} / \mathrm{L}$ & $\mathrm{HCV}-\mathrm{Ab}$ & $(-)$ & $\mathrm{ng} / \mathrm{m} \mathrm{L}$ \\
\hline $\mathrm{Na}$ & 139 & $\mathrm{mEq} / \mathrm{L}$ & CRP & 5.4 & $\mathrm{mg} / \mathrm{dL}$ & HCV-RNA & $(-)$ & $\mathrm{U} / \mathrm{mL}$ \\
\hline K & 4.1 & $\mathrm{mEq} / \mathrm{L}$ & IgG & 1,104 & $\mathrm{mg} / \mathrm{d} \mathrm{L}$ & HEV-IgA & $(-)$ & $\mathrm{U} / \mathrm{mL}$ \\
\hline $\mathrm{Cl}$ & 105 & $\mathrm{mEq} / \mathrm{L}$ & IgA & 235 & $\mathrm{mg} / \mathrm{d} \mathrm{L}$ & PT & 98 & $\%$ \\
\hline $\mathrm{Ca}$ & 9.5 & $\mathrm{mg} / \mathrm{d} \mathrm{L}$ & IgM & 212 & $\mathrm{mg} / \mathrm{dL}$ & AFP & 2 & $\mathrm{ng} / \mathrm{mL}$ \\
\hline
\end{tabular}

used to treat adult-onset RA and the systemic form of juvenile idiopathic arthritis (JIA) (7-9). In addition, tocilizumab is approved for the treatment of Castleman's disease, a rare lymphoproliferative condition featuring hyperplasia, recorded from Japan (10). Blocking of IL-6R by tocilizumab is associated with a higher risk of chronic hepatitis B infection (11), but not acute infections, compared to other biologics, including anti-TNF $\alpha$ antibody.

Few reports on tocilizumab-treated RA patients with systemic infections caused by cytomegalovirus (CMV) reactivation have so far been published. We herein report that CMV reactivation induced acute hepatitis and gastric erosions in an RA patient under tocilizumab therapy.

\section{Case Report}

A 54-year-old woman had been prescribed an oral corticosteroid (prednisolone, $3 \mathrm{mg}$ daily) and methotrexate (MTX, $8 \mathrm{mg}$ weekly) to treat RA. As the disease activity was not adequately controlled, she was additionally prescribed the anti-IL-6 receptor antibody tocilizumab, while the doses of corticosteroid and MTX had not changed for approximately 2 years. After 19 days on such therapy, she presented at our hospital with a high fever, loss of appetite, epigastralgia, and lymphadenopathy. On admission, her body temperature was $39.5^{\circ} \mathrm{C}$ and her blood pressure was 122/69 $\mathrm{mmHg}$. Her regular heart rate was 94 beats/min and with a respiratory rate of $20 / \mathrm{min}$ at an oxygen saturation level of $98 \%$ in room air. Laboratory data on admission included a white blood cell count of 8,200/L, including 55.0\% lymphocytes and $4 \%$ atypical lymphocytes, a hemoglobin level of $12.5 \mathrm{~g} / \mathrm{dL}$, and a platelet count of $25.7 \times 10^{4} / \mathrm{L}$. The Creactive protein (CRP) level was $5.4 \mathrm{mg} / \mathrm{dL}$. The hepatobiliary functional test was abnormal, although she had no history of chronic liver disease. CMV related data indicated reactivation with viremia (Table). Ultrasonography (Fig. 1a) and computed tomography (CT) (Fig. 1b, c) revealed hepatosplenomegaly and an edematous gall bladder, but without ascites. These data were compatible with acute hepatitis.
Upper gastrointestinal endoscopy revealed multiple diffuse erosions at the gastric antrum and body (Fig. 2a, b) induced by CMV infection, as confirmed immunohistochemically (Fig. 2c, d). We therefore diagnosed the patient with CMV infection with acute hepatitis and gastric erosions caused by anti-IL-6 receptor antibody therapy. No retinitis or central nervous system involvement was evident. We prescribed the anti-CMV drug ganciclovir for 14 days to treat the patient's CMV viremia and impaired general condition (suggestive of a severe infection). Her general condition rapidly improved, the hepatobiliary functional test data normalized, and hepatosplenomegaly and the gastric erosions disappeared (Fig. 2e, f). She was discharged 18 days after the commencement of ganciclovir treatment (Fig. 3).

\section{Discussion}

We herein reported the reactivation of CMV-induced acute hepatitis and gastric erosions in a RA patient on tocilizumab treatment who had previously received long-term corticosteroid and MTX therapy. We presumed that the patient was severely immunocompromised and at a high risk of serious infection (12). Therefore, we prescribed ganciclovir for 14 days to treat CMV reactivation and prevent severe disease, which improved the patient's general condition.

CMV is a persistent herpesvirus infecting $45-100 \%$ of healthy individuals (13). Three principal types of CMV infection are recognized. One is a congenital canal infection and one a primary infection (often asymptomatic and selflimited) in immunocompetent individuals. The third type of infection is reactivation in immunocompromised patients, such as those who have received transplants or who are treated with biological agents and corticosteroids. Such infections may cause severe morbidity and even mortality (14). Recently, not only post-transplant patients, but also those taking biological agents (i.e., RA patients) such as tocilizumab and anti-TNF- $\alpha$ antibodies (which are widely recognized to be safe and efficacious), have been shown to be at risk of various infections (15). When such agents are pre- 
a

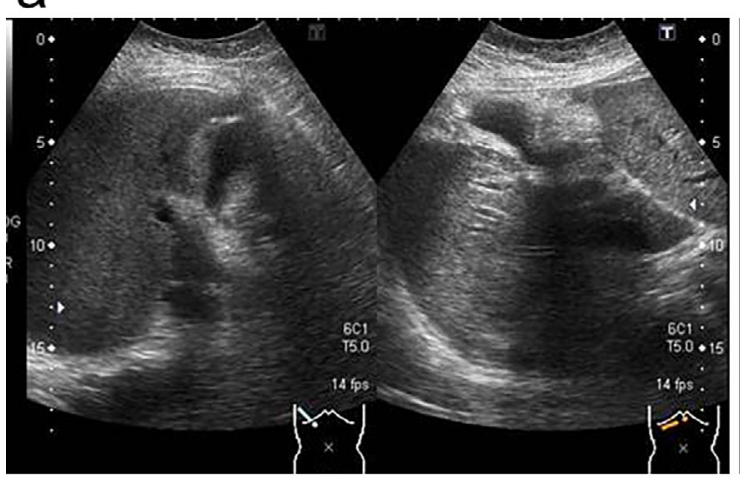

C

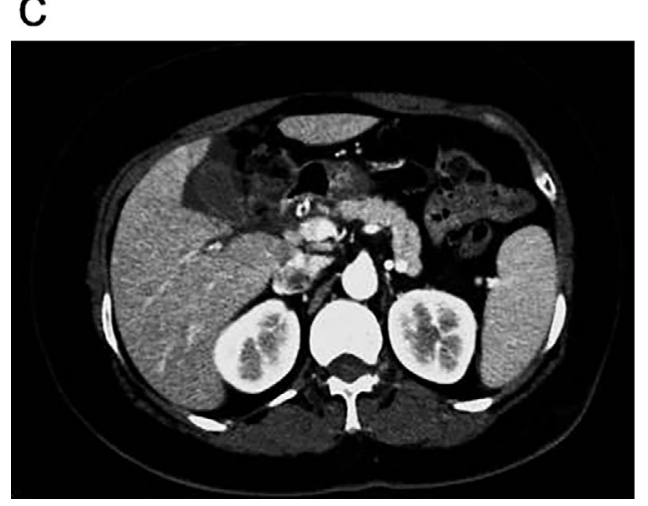

b

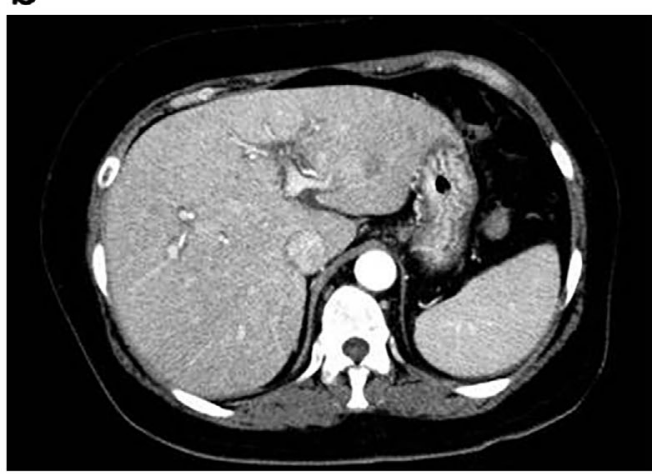

Figure 1. a: Abdominal ultrasonography showing hepatomegaly and an edematous gall bladder. b: An abdominal CT scan showing hepatomegaly and an edematous gall bladder. c: An abdominal CT scan showing that the peri-portal region was uneven in appearance.
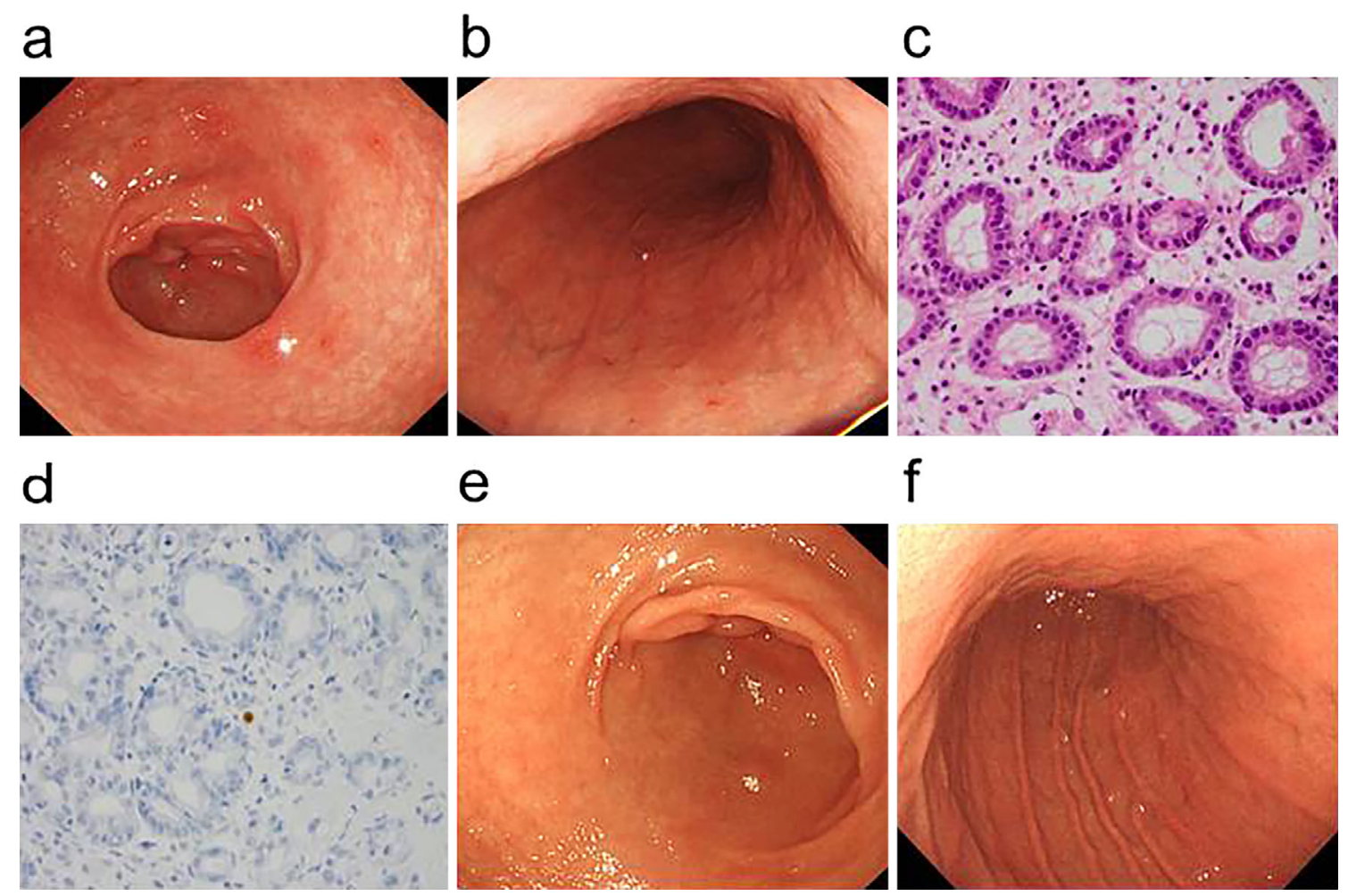

Figure 2. The endoscopic appearance of the stomach. a: Diffuse gastric erosions in the antrum of the stomach. b: Diffuse gastric erosions in the body of the stomach. c: Histologically, Hematoxylin and Eosin staining reveals a CMV infection. d: Immunohistochemically, CMV staining is positive. e: Disappearance of the diffuse gastric erosions in the antrum of the stomach. $f$ : Disappearance of the diffuse gastric erosions in the body of the stomach. 


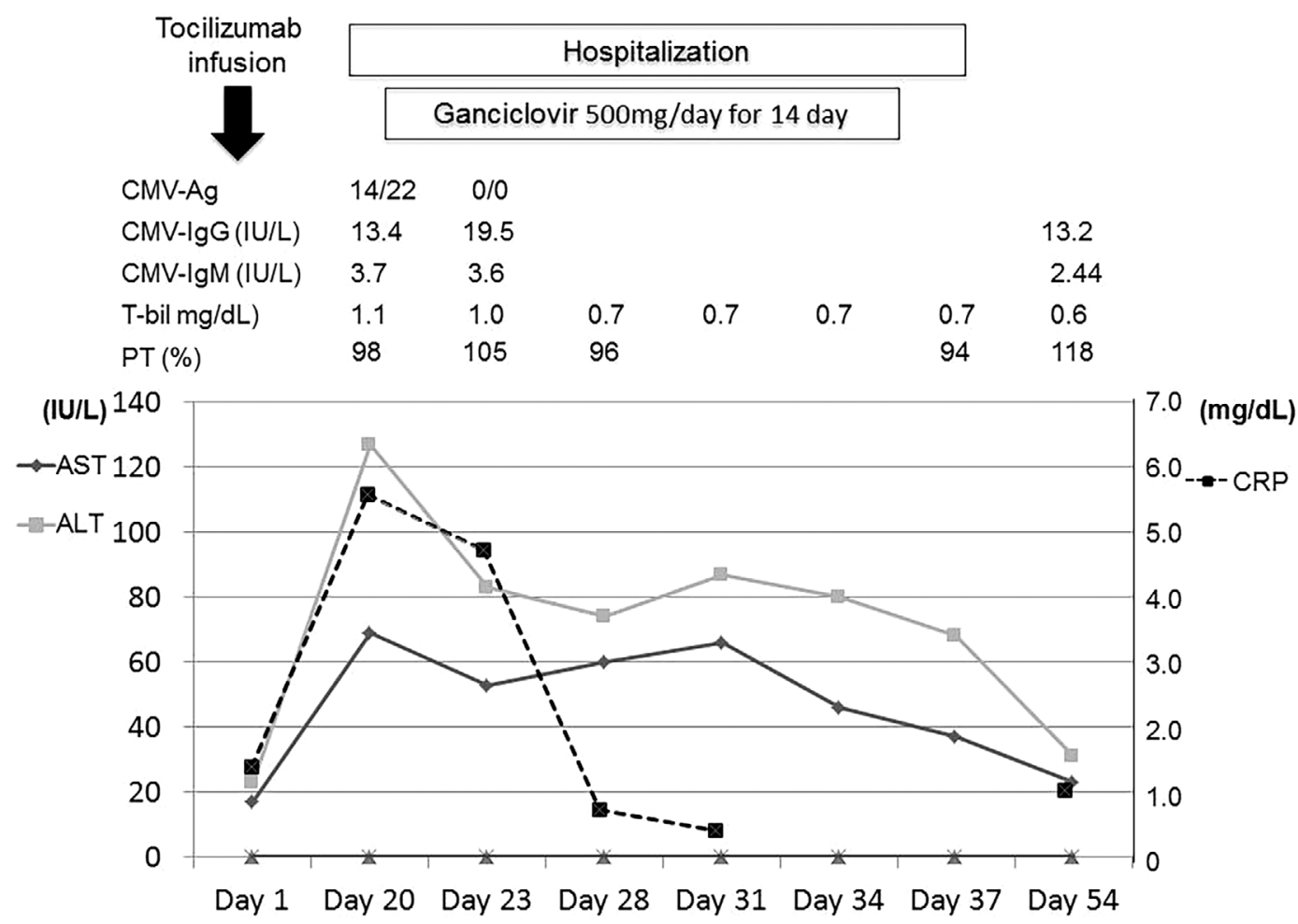

Figure 3. Clinical course.

scribed, surveillance for infection with, for example, Mycobacterium tuberculosis is essential (16). In our case, a prior serological examination indicated that she had previously been infected with $\mathrm{CMV}$, while her clinical features were similar to those of infectious mononucleosis caused by CMV primary infection. It is likely that the systemic CMV infection had been caused by reactivation while she was in an immunocompromised state, which resulted from years of treatment with tocilizumab and other immunosuppressive agents (MTX and corticosteroids). Thus, anti-viral agents may be necessary in patients receiving tocilizumab to prevent mortality because the CRP response is occasionally masked by the inhibition of IL-6 (15).

IL-6 is a key humoral mediator of the pathogenesis of multiple diseases, affecting various immune cells, including $\mathrm{T}$ and $\mathrm{B}$ cells. Therefore, a reduction in the IL- 6 levels by tocilizumab impairs the immune reaction to infection $(3,5)$, creating an immunosuppressed state. Many cells of the immune system are involved in the immune response to CMV; these include antibody-producing cells, NK cells, and CD4and CD8-positive $\mathrm{T}$ cells. In particular, antigen-specific CD8-positive $\mathrm{T}$ cells are dysfunctional upon CMV reactivation (17). As IL-6 plays crucial roles in B-cell proliferation, antibody production, and T-cell differentiation and cytotoxicity, the inhibition of IL-6/IL-6R complex formation may trigger the dysfunction of antigen-specific CD8-positive $\mathrm{T}$ cells. A previous study reported that IL-6 knockout mice were more susceptible to infection by herpes simplex virus, a member of the herpes family of viruses, which includes CMV (18). Infections by two other herpes viruses, chronic active Epstein-Barr virus (EBV) and herpes zoster, were ob- served in RA patients on tocilizumab therapy (19-21). Furthermore, CMV-induced pneumonitis was reported in an RA patient who had received tocilizumab, oral corticosteroid (prednisolone, $5 \mathrm{mg}$ daily), and MTX (7.5 mg weekly) therapy (22). In contrast, a prospective study suggested that treatment with tocilizumab and MTX do not affect EBV and herpes virus 6 viral loads in JIA subjects (23). A recent Cochrane Review suggested that the risk of serious infections in patients taking tocilizumab was not higher than that in patients given placebos (24). Although RA patients on tocilizumab therapy are not at a significantly high risk for reactivation of $\mathrm{CMV}$, the potential for CMV reactivation remains. In our case, the patient was not prescribed more MTX and corticosteroid than is typically given for RA treatment. In addition, her lymphocyte and immunoglobulin levels did not increase, and her nutritional state was not impaired. Further studies are necessary to determine the risks for CMV reactivation and identify the mechanisms of reactivation in patients on tocilizumab therapy to prevent CMV-related mortality.

In conclusion, we herein presented a case in which reactivation of CMV caused an infection in a RA patient receiving tocilizumab in combination with other immunosuppressive agents. These results indicated the importance of defining the high-risk population for CMV reactivation among patients on tocilizumab therapy and identifying appropriate treatment strategies for these patients.

The authors state that they have no Conflict of Interest (COI). 


\section{References}

1. Scott DL, Wolfe F, Huizinga TW. Rheumatoid arthritis. Lancet 376: 1094-1108, 2010.

2. Dasgupta B, Corkill M, Kirkham B, Gibson T, Panayi G. Serial estimation of interleukin- 6 as a measure of systemic disease in rheumatoid arthritis. J Rheumatol 19: 22-25, 1992.

3. Kishimoto T. The biology of interleukin-6. Blood 74: 1-10, 1989.

4. Liuzzi JP, Lichten LA, Rivera S, et al. Interleukin-6 regulates the zinc transporter Zip14 in liver and contributes to the hypozincemia of the acute-phase response. Proc Natl Acad Sci USA 102: 68436848, 2005.

5. Nishimoto N, Kishimoto T. Interleukin 6: from bench to bedside. Nat Clin Pract Rheumatol 2: 619-626, 2006.

6. Oldfield V, Dhillon S, Plosker GL. Tocilizumab. Drugs 69: 609632, 2009.

7. Nam JL, Winthrop KL, van Vollenhoven RF, et al. Current evidence for the management of rheumatoid arthritis with biological disease-modifying antirheumatic drugs: a systematic literature review informing the EULAR recommendations for the management of RA. Ann Rheum Dis 69: 976-986, 2010.

8. Smolen JS, Aletaha D, Koeller M, Weisman MH, Emery P. New therapies for the treatment of rheumatoid arthritis. Lancet 370: 1861-1874, 2007.

9. Singh JA, Beg S, Lopez-Olivo MA. Tocilizumab for rheumatoid arthritis. Cochrane Database Syst Rev (7): CD008331, 2010.

10. Matsuyama M, Suzuki T, Tsuboi $H$, et al. Anti-interleukin-6 receptor antibody (tocilizumab) treatment of multicentric Castleman's disease. Intern Med 46: 771-774, 2007.

11. Nagashima T, Minota S. Long-term tocilizumab therapy in patients with rheumatoid arthritis and chronic hepatitis B. Rheumatology 47: 1838-1840, 2008.

12. Feist E, Burmester GR. Is tocilizumab in combination with traditional DMARDs safe and effective for patients with active RA? Nat Clin Pract Rheumatol 5: 128-129, 2009.

13. Cannon MJ, Schmid DS, Hyde TB. Review of cytomegalovirus seroprevalence and demographic characteristics associated with infection. Rev Med Virol 20: 202-213, 2010.
14. Griffi T. Burden of disease associated with human cytomegalovirus and prospects for elimination by universal immunisation. Lancet Infect Dis 12: 790-798, 2012.

15. Lang VR, Englbrecht M, Rech J, et al. Risk of infections in rheumatoid arthritis patients treated with tocilizumab. Rheumatology (Oxford) 51: 852-857, 2012.

16. Saunders BM, Frank AA, Orme IM, Cooper AM. Interleukin-6 induces early gamma interferon production in the infected lung but is not required for generation of specific immunity to Mycobacterium tuberculosis infection. Infect Immun 68: 3322-3326, 2000.

17. Ozdemir E, St John LS, Gillespie G, et al. Cytomegalovirus reactivation following allogeneic stem cell transplantation is associated with the presence of dysfunctional antigen-specific $\mathrm{CD} 8^{+} \mathrm{T}$ cells. Blood 100: 3690-3697, 2002.

18. Murphy EA, Davis JM, Brown AS, Carmichael MD, Ghaffar A, Mayer EP. Effect of IL-6 deficiency on susceptibility to HSV-1 respiratory infection and intrinsic macrophage antiviral resistance. J Interferon Cytokine Res 28: 589-595, 2008.

19. Ogawa J, Harigai M, Akashi T, et al. Exacerbation of chronic active Epstein-Barr virus infection in a patient with rheumatoid arthritis receiving humanized anti-interleukin-6 receptor monoclonal antibody. Ann Rheum Dis 65: 1667-1669, 2006.

20. Kubandova Z, Mathieu S, Pourtier C, Soubrier M. Serious herpes zoster in rheumatoid arthritis under anti-interleukin-6 receptor antibody. Joint Bone Spine 77: 623-624, 2010.

21. Roux C, Breuil V, Albert C, et al. Ophthalmic herpes zoster infection in patients with rheumatoid arthritis who were treated with tocilizumab. J Rheumatol 38: 399, 2011.

22. van Duin D, Miranda C, Husni E. Cytomegalovirus viremia, pneumonitis, and tocilizumab therapy. Emerg Infect Dis 17: 754-756, 2011.

23. Kawada J, Iwata N, Kitagawa Y, Kimura H, Ito Y. Prospective monitoring of Epstein-Barr virus and other herpesviruses in patients with juvenile idiopathic arthritis treated with methotrexate and tocilizumab. Mod Rheumatol 22: 565-570, 2012.

24. Singh JA, Wells GA, Christensen R, et al. Adverse effects of biologics: a network meta-analysis and Cochrane overview. Cochrane Database Syst Rev (2): CD008794, 2011.

(C) 2016 The Japanese Society of Internal Medicine http://www.naika.or.jp/imonline/index.html 